\title{
Contingent Trade Policy and Economic Efficiency ${ }^{1}$
}

\author{
Phillip McCalman ${ }^{2} \quad$ Frank Stähler ${ }^{3} \quad$ Gerald Willmann ${ }^{4}$
}

April 2011

\footnotetext{
${ }^{1}$ Paper presented at several conferences and seminars. We thank Nic Schmitt and participants for helpful comments and suggestions.

${ }^{2}$ Department of Economics, University of California, Santa Cruz CA 95064, USA, email: mccalman@ucsc.edu

${ }^{3}$ Department of Economics and CESifo, University of Würzburg, Sanderring 2, D-97070 Würzburg, Germany, email: frank.staehler@uni-wuerzburg.de

${ }^{4}$ Department of Economics, Katholieke Universiteit Leuven, Naamsestraat 69, 3000 Leuven, Belgium, email: gerald.willmann@econ.kuleuven.be
} 


\begin{abstract}
This paper develops an efficiency theory of contingent trade policies. We model the competition for a domestic market between one domestic and one foreign firm as a pricing game under incomplete information about production costs. The cost distributions are asymmetric because the foreign firm has to pay a trade cost. We show that the foreign firm prices more aggressively to overcome its cost disadvantage. The resulting possibility of an inefficient allocation justifies the use of contingent trade policy on efficiency grounds. Contingent trade policy that seeks to maximize global welfare can avoid the potential inefficiency. National governments, on the other hand, make excessive use of contingent trade policy due to rent shifting motives. The expected inefficiency of national policy is larger (smaller) for low (high) trade costs compared to the laissez-faire case. In general, there is no clear ranking between the laissez-faire outcome and a contingent national trade policy. Keywords: Contingent Trade Policy, Efficiency.

JEL Classifications: F12, F13.
\end{abstract}




\section{Introduction}

Contingent protection occupies an interesting niche within the trade policy literature; if certain pre-specified criteria are met, which can be substantiated through quasi-judicial process, then a country feels entitled to impose a trade barrier. Classifying policies from this procedural perspective implies that contingent protection covers a range of policies such as anti-dumping (AD), countervailing duties (CVD) and safeguards/escape clause actions. While the motivation and application of these policies varies, the pre-determined criteria for their use lends an air of legitimacy to their implementation. ${ }^{1}$ However, regardless of the apparent legitimacy afforded by an inquisitional methodology, these policies tend to be criticized due to their excessive use which stems from the malleable nature of the criteria employed. In short, while there may exist some criteria which justify a policy intervention (i.e. some market failure), government failure tends to offset any potential benefits. ${ }^{2}$ However, it is not immediately obvious that this outcome is always guaranteed. Hence the objective of this paper is to distinguish the circumstances under which policy action may potentially be effective from those when it will not.

To explore the issues associated with this question we construct a simple framework that allows for both market and - potentially - government failure. The setting we choose to focus on resembles a dumping style model. Our point of departure is to move the rationale for policy intervention away from the usual motivation of predation toward a broader and more relevant concept of allocative efficiency. ${ }^{3}$ Therefore we focus on the question of who should be producing what and whether trade policy, in the form of duties, has a role to play in improving efficiency. If a policy-maker has complete information about the relevant

\footnotetext{
${ }^{1}$ The original motivation for AD policy is based in the logic of predation, while CVD is motivated by "unfair" foreign policies. In contrast, the use of safeguards has been justified on the basis of maintaining sufficient flexibility to ensure the continued adherence to a trade agreement (see Bagwell and Staiger (1990)). Alternatively, contingent trade policy can be regarded as the remains of a gradual reduction of trade barriers; see Chisik (2003) for model of gradualism in free trade agreements.

${ }^{2}$ For instance $\mathrm{AD}$ duties are often seen as gratuitous in size - with duties of the order of $100 \%$ not unusual, see Bown (2007).

${ }^{3}$ Our focus on price discrimination is reminiscent of Brander and Krugman (1983). However, while dumping occurs in their framework, it is not the focus of their analysis. As discussed below, we adopt a market structure that emphasizes the resource allocation issues and provides a clear policy benchmark.
} 
costs, then determining the optimal allocation of resources is straightforward and the only real concern is one of policy failure. This is the element - policy failure - that the previous literature has focused on and sought to stress. If the policy-maker is incompletely informed about the cost structure, then both the mechanics of competition become more involved and the criteria for determining government intervention becomes less transparent. In this setting it is possible to have a market failure that cannot be adequately addressed by government intervention. It is this environment of asymmetric information in which we couch our analysis. ${ }^{4}$

More specifically, we develop a model of international competition where neither firm is reliably informed of the other's cost structure. ${ }^{5}$ To sharpen the implications of competition, we assume that firms produce a homogeneous product and compete in prices; generating a winner-take-all scenario. Under complete information this set-up achieves allocative efficiency. Allocative efficiency is also achieved under the assumption of symmetry when firms are incompletely informed (that is, both firms are assumed to take cost draws from the same probability distribution). The virtue of this set-up is that under either complete information or asymmetric information there is no market failure and therefore no need for government intervention. This provides us with a clear and unambiguous benchmark. However, as a model of international competition it is lacking a critical feature: transport costs. The introduction of transport costs implies that the firms are no longer symmetric. This small, but realistic change has profound implications for the allocation of resources: the higher cost firm can ultimately be the sole supplier in the market. This market failure has a clear source; since the foreign firm is at a disadvantage due to transport costs it prices more aggressively than the domestic firm. Consequently, when both firms have the same cost draws (inclusive of transport costs in case of the foreign firm), the foreign firm will quote a strictly lower price. This implies two things. First, in the neighborhood of these cost draws it is possible to identify outcomes where the higher cost foreign firm serves the

\footnotetext{
${ }^{4} \mathrm{~A}$ policy process distorted by political influence can also result in government failure. In this paper we abstract from this consideration and focus on the issue of whether or not a domestic government can intervene in an efficiency enhancing manner.

${ }^{5}$ For empirical evidence of firms operating in a stochastic environment, see Hillberry and McCalman (2011).
} 
domestic market; an inefficient allocation of resources. Moreover, this inefficiency can be very pronounced, representing up to $15 \%$ of ex ante surplus. Second, the foreign firm prices more aggressively abroad than in their local market, i.e. dumping occurs. ${ }^{6}$

Given such market failure, the question we address in this paper is whether the use of contingent trade policy can remedy the inefficiency and achieve an efficient allocation of resources. ${ }^{7}$ One important obstacle the policymaker faces is that production costs are private information. Can a government infer which firm is the lower cost producer for any given set of cost draws from the firms' pricing behavior? And if the answer is positive, does the announcement of a mechanism for intervention still enable such an inference to be drawn? ${ }^{8}$ We show that it is possible for a government to infer the costs in the absence of policy, and also to design a contingent trade policy scheme that preserves this inferential ability; that is, a first best outcome can potentially be achieved.

The ability to achieve the first best, however, does not imply that it will be implemented. We consider first the case of a global institution seeking to maximize global welfare. Such an institution could implement a first best policy. However, its distributional implications will most likely be asymmetric, and not offer unambiguous gains to both countries. Hence such an institution might be vetoed. We study this case mainly as a benchmark. The second and more realistic scenario is the case where it is up to national governments to implement contingent trade policy. National policymakers, however, do not have any incentive to implement the first best outcome. Seeking to maximize national welfare, they exploit the rent shifting aspect of protection and make excessive use of contingent trade policies. The resulting equilibrium will thus again be inefficient, this time because of rent shifting.

The presence of two inefficiencies — one stemming from market failure, the other from

\footnotetext{
${ }^{6}$ Dumped imports are typically defined to be foreign products exported at prices below "fair value," that is, either below the prices of comparable products for sale in the domestic market of the exporting country or below costs of production.

${ }^{7} \mathrm{~A}$ number of other papers have considered an environment of asymmetric information: Miyagiwa and Ohno (2007), Matschke and Schottner (2008) and Kolev and Prusa (2002). However, these papers are concerned with the implications of anti-dumping policy on firm behavior (output, prices and profits) and do not investigate whether anti-dumping duties can achieve a first best outcome.

${ }^{8}$ Even in a complete information setting, Staiger and Wolak (1992) and Anderson (1992) make the point that the mere existence of anti-dumping policy will alter firms behavior.
} 
government failure - obviously raises the question which of them is quantitatively more important. Our analysis shows that the allocative inefficiency dominates at high trade costs. For lower trade costs, on the other hand, it is the inefficiency caused by rent shifting motivated policy that is larger. At high trade costs, it is therefore preferable to allow national governments to conduct contingent trade policy, while for low trade costs the laissez-faire regime welfare-dominates nationally conducted policy.

This paper is not the first paper on contingent trade policies, but there is a large and extensive theoretical and empirical literature on anti-dumping, countervailing duties and safeguards/escape clauses (for an overview, see for example Chapter 7 in Feenstra (2004) and Blonigen and Prusa (2003)). We regard our paper as complementary to a newer literature whose objective is to explain the flexibility of trade agreements and the existence of contingent trade policies as a response to potential shocks. ${ }^{9}$ Our paper characterizes the conditions under which contingent trade policies are feasible (that is, can be "successfully"implemented), and it offers a rationale for why countries may have this discretion rather than be bound by a fixed policy. While this has a similar emphasis in the flexibility literature, the innovation of our paper is that we allow for an interplay between the policy environment and the actions of firms - that is, we allow the announcement of the policy rule to change firm behavior. So rather than having a given degree of uncertainty and choosing the optimal design of the institution under various constraints (that is, ability of adjudicators), we examine how the institutions themselves can either enhance or undermine their own effectiveness.

The remainder of the paper is organized as follows: In Section 2, we set up the model, solve for the price functions, and show that an allocative inefficiency can arise. Section 3 presents the analysis of a contingent trade policy that maximizes global welfare. In Section 4, we analyze the policy a national government seeking to maximize national welfare would enact, and compare it to the laissez-faire case. Section 5, finally, offers concluding remarks.

\footnotetext{
${ }^{9}$ One strand of this literature considers contingent trade policies as an insurance against shocks which keeps the trade agreement viable, see for example Fischer and Prusa (2003). Other papers have even endogenized the scope of an agreement by explaining the contract incompleteness by costly contracting, see Horn and Staiger (2010), Maggi and Staiger (2008) and Maggi and Staiger (2009). For a model with costly state-verification, see Beshkar and Bond (2010).
} 


\section{The model}

We begin our analysis by considering a baseline setup without contingent trade policy. A key feature of the framework presented here, driven by informational asymmetries, will be the possibility of market failure (i.e. a misallocation of resources), while it is also possible that the laissez-faire equilibrium allocates resources efficiently. Our setting features two firms - a domestic firm and a foreign firm - which both produce a homogeneous product for the domestic market. Consumers in this market have unit demands, a maximum willingness to pay of one, and without further loss of generality, we normalize the size of consumers to one. In choosing a model of homogeneous goods with inelastic demand, we squarely place the emphasis on the location of production as being the sole determinant of economic efficiency. To sharpen the resource allocation issue, let firms compete against each other in prices. That is, consumers buy from firm $i$ if $p_{i}<p_{j}$ (and randomize in case of equal prices). Importantly, we assume that the firms' production costs, $c_{1}$ and $c_{2}$, are private information. That is, a firm knows its own cost but does not know the cost realization of its rival. As is standard in models such as ours, assume that the beliefs of firm $i$ about the production cost of its opponent, $c_{j}$, are described by a cdf $F(c)$. That is, costs are drawn from the same distribution. Note that the asymmetry of information alone is not enough to generate a misallocation of resources. To obtain a potential market failure, we rely on adding the plausible feature that the foreign firm must pay a per unit trade cost of $t$ (which is assumed to be common knowledge).

By adding the transport cost to the model, it now has a feature that potentially induces market failure. At the same time, adding this feature complicates the analysis since it is possible for the foreign firm to receive a cost draw that - once the transport cost is added

- exceeds the domestic consumer's willingness to pay. In case of such a high cost, the foreign firm will clearly not be competitive in the domestic market, and leave the market to the domestic firm. To deal (or rather to avoid dealing) with this case, we add a pre-stage to our model where the foreign firm has to decide whether to enter the domestic market. If it decides to do so, it has to pay a market-entry cost of $\epsilon$, which can be observed by the domestic firm. The investment required to enter the market can be relatively small, for example the search cost of finding a wholesaler and/or retailer. Importantly, the entry 
decision of the foreign firm signals a certain productivity range, which allows the domestic firm to update its beliefs about its opponent's productivity. If the foreign firm does not enter the market, the domestic firm is a monopolist and will set $p_{1}$ equal to one. In what follows, we shall focus on cases in which entry occurs. ${ }^{10}$ Table 1 summarizes the sequence of decisions in our model, which can be solved backwards in the usual fashion.

Table 1: Game structure

Stage 0 :
Both the domestic and the foreign firm draw
their marginal production costs from $[0,1]$.
Productions costs are private information.
Stage $I$ :
The foreign firm decides on entry which warrants
a cost of size $\epsilon, \epsilon \geq 0$,
observable by the domestic firm.
Stage $I I$ :
If the foreign firm has not entered, the domestic firm sets its price.
Stage III:
In case of a contingent trade policy, the regulating authority
observes prices and decides whether to impose
a tariff on foreign imports.

In order to solve for the equilibrium, we start from the assumption (to be verified later) that the optimal pricing functions $p_{i}\left(c_{i}\right)$ are monotone and strictly increasing in costs. This implies that there exist inverse pricing functions that are also monotone and strictly increasing in prices. We denote these inverse pricing functions by $\phi_{i}\left(p_{i}\right)$, i.e. price $p_{i}$ is associated with a cost $c_{i}=\phi_{i}\left(p_{i}\right)$. These costs are drawn from a common distribution, characterized by the cumulative distribution function $F(c)$. The trade cost and the entry decision of the foreign firm imply that the (updated) beliefs over the other firm's cost will

\footnotetext{
${ }^{10}$ The other case is trivial and not of particular interest. We should keep in mind, though, that our analysis is conditional on entry, and that a change in $t$ also changes the probability of entry.
} 
be asymmetric across firms. Let $F_{1}\left(c_{1}\right)$ denote the distribution of the cost of the domestic firm, which is identical to the underlying distribution $F(c)$. The distribution of the cost of the foreign firm, $F_{2}\left(c_{2}\right)$, on the other hand, is based on a Bayesian update from $F(c)$ in line with the observation that the foreign firm enters the market.

Consider now the firms' pricing decisions. Suppose the domestic firm sets a price of $p_{1}$, and the foreign firm employs the inverse pricing function $\phi_{2}\left(p_{2}\right)$. The probability that the domestic firm loses the market in the Bertrand pricing game is equal to $F_{2}\left(\phi_{2}\left(p_{1}\right)\right)$, which captures the probability that the foreign firm has a cost below the threshold value that is implied by applying its inverse pricing function to the price $p_{1}$. In this case, the domestic firm's profit is zero as it is undercut by the foreign firm. The domestic firm wins only if $p_{1}<p_{2}$, that is, its chances of winning are equal to $1-F_{2}\left(\phi_{2}\left(p_{1}\right)\right)$. A similar argument applies to the foreign firm. Hence we can write the expected profits of both firms as follows:

$$
\begin{aligned}
& \pi_{1}\left(p_{1} ; c_{1}\right)=\left(1-F_{2}\left(\phi_{2}\left(p_{1}\right)\right)\right)\left(p_{1}-c_{1}\right), \\
& \pi_{2}\left(p_{2} ; c_{2}\right)=\left(1-F_{1}\left(\phi_{1}\left(p_{2}\right)\right)\right)\left(p_{2}-c_{2}-t\right),
\end{aligned}
$$

where the first term in each expression on the RHS is the probability of winning the market, and the second factor is the profit margin. Note that the foreign firm has an extra cost of $t$ to deduct from it margin.

Each firm chooses its price in order to maximize expected profit. The resulting firstorder conditions for interior solutions are given by:

$$
\begin{aligned}
& \left(1-F_{2}\left(\phi_{2}\left(p_{1}\right)\right)\right)-f_{2}\left(\phi_{2}\left(p_{1}\right)\right) \phi_{2}^{\prime}\left(p_{1}\right)\left(p_{1}-c_{1}\right)=0, \\
& \left(1-F_{1}\left(\phi_{1}\left(p_{2}\right)\right)\right)-f_{1}\left(\phi_{1}\left(p_{2}\right)\right) \phi_{1}^{\prime}\left(p_{2}\right)\left(p_{2}-c_{2}-t\right)=0,
\end{aligned}
$$

where $f_{i}\left(c_{i}\right)=F_{i}^{\prime}\left(c_{i}\right)$ denotes the density function corresponding to $F_{i}\left(c_{i}\right)$.

In order to make the model tractable, we make the following two assumptions:

Assumption 1 Costs are distributed uniformly over the unit interval, i.e. $F(c)=c$.

Assumption 1 will allow us to find closed form solutions for the optimal pricing functions. Furthermore, the update of beliefs is straightforward: Let $\gamma$ denote the critical foreign type which is indifferent between entry and no entry into the domestic market. If the domestic 
firm believes that only the (productive) types will enter for which $c_{2} \leq \gamma$, it follows that $F_{2}\left(c_{2}\right)=c_{2} / \gamma$. Since the most intense price competition will occur if the foreign can enter easily, we also assume the following:

Assumption 2 The investment cost the foreign firm has to pay for entering the market is very small, i.e. $\epsilon \simeq 0$.

Both assumptions enable us to determine the optimal pricing behavior for the laissezfaire case without policy intervention:

Lemma 1 Under Assumptions 1 and 2 and without policy intervention, $F_{2}\left(c_{2}\right)$ equals $1 /(1-t)$ and firm 2 enters if $c_{2} \leq 1-t$. Furthermore, in case of entry, the equilibrium pricing functions are given by:

$$
\begin{aligned}
& p_{1}\left(c_{1}\right)=1-\frac{\sqrt{1+2\left(1-c_{1}\right)^{2} K_{1}}-1}{2\left(1-c_{1}\right) K_{1}} \\
& p_{2}\left(c_{2}\right)=1-\frac{\sqrt{1+2\left(1-\left[c_{2}+t\right]\right)^{2} K_{2}}-1}{2\left(1-\left[c_{2}+t\right]\right) K_{2}}
\end{aligned}
$$

where

$$
K_{1}=\frac{1}{2} \frac{t(2-t)}{(1-t)^{2}} \geq 0 \text { and } K_{2}=-K_{1} \leq 0 .
$$

Proof: See Appendix A.1.

Note that our solution includes the special case of symmetry when $t=0$. In this case, both pricing functions simplify and take the form:

$$
p_{i}\left(c_{i}\right)=\frac{1}{2}+\frac{c_{i}}{2}
$$

Let us return to the case of a strictly positive trade cost. Figure 1 depicts an example of the pricing functions derived above (where we have chosen $t$ to equal 0.2). Note that the pricing strategy of the foreign firm is depicted as a function of total cost, $c_{2}+t$, and is represented by the lower of the two curves, the one that starts at $t=0.2$. Now consider the following notion of aggressiveness: A firm's pricing strategy is more aggressive than that of its rival if it has the larger overall cost (which includes $t$ for the foreign firm) when charging the same price. Comparing the two firms' strategies, there is a clear result: 


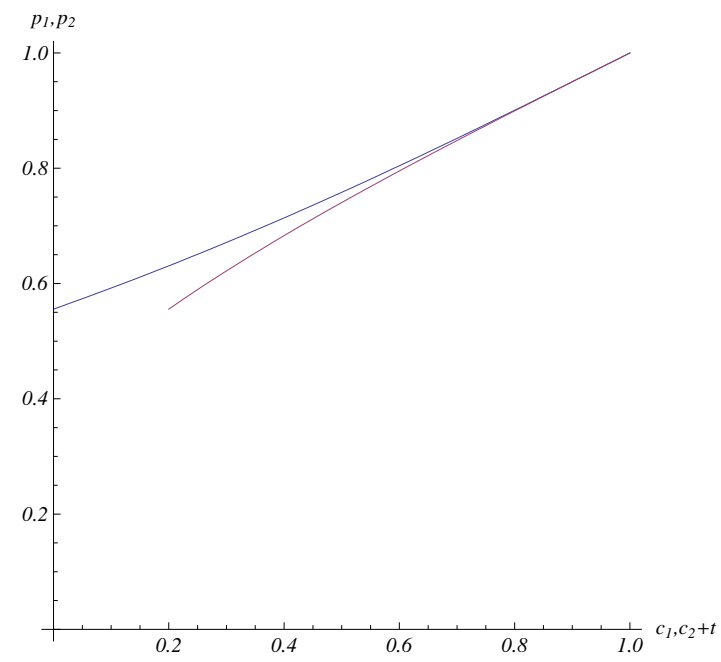

Figure 1: Equilibrium price functions for $t=0.2$.

Lemma 2 The foreign firm prices more aggressively than the domestic firm.

Proof: See Appendix A.1.

The intuitive reason for this result is that the foreign firm wants to make up for its inherent cost disadvantage (caused by the trade cost $t$ ) in order to increase its probability of winning.

One important consequence of the foreign firm's aggressive pricing behavior is the possibility that it offers the lower price even though it has the higher overall cost. Hence our framework has the potential to generate an inefficient allocation of resources. Note that it is not always the case that the allocation is inefficient when the foreign firm offers the lower price. The inefficiency only arises when the foreign firm offers the lower price and has the higher cost. Formally, the outcome is inefficient whenever $p_{2}<p_{1}$ and $c_{2}+t>c_{1}$.

While this model admits the possibility of an inefficient outcome it is natural to ask how likely this is. Appendix A.1 shows that the probability of an inefficient trade is given by:

$$
\operatorname{prob}=\frac{1}{2}+\frac{1}{(2-t)(1-t)}-\frac{1}{1-t} .
$$

Not surprisingly the likelihood of an inefficient outcome is a function of the size of the trade 

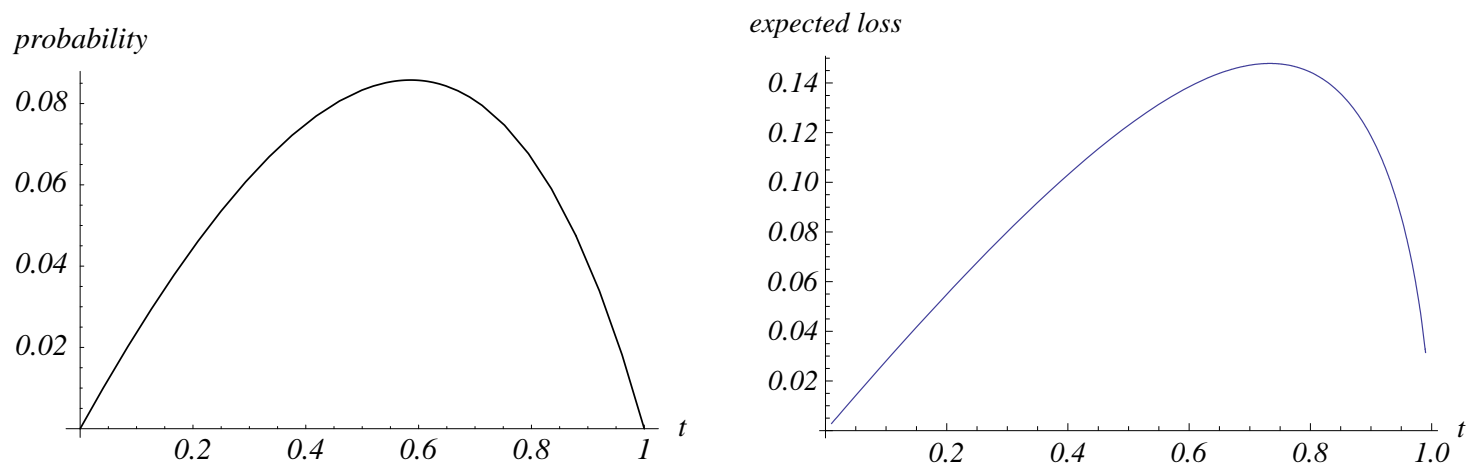

Figure 2: Probability and Conditional Expected Loss under Laissez-faire

cost. To examine this relationship more closely, differentiate with respect to the trade cost:

$$
\frac{\partial p r o b}{\partial t}=\frac{t^{2}-4 t+2}{2\left(t^{2}-4 t+4\right)}
$$

This derivative is positive for low trade costs but becomes negative for higher $t$. The resulting non-monotonicity of the probability of inefficiency is displayed in Figure 2. Figure 2 also shows the expected loss, conditional upon inefficient entry, which can rise up to significant $15 \%$ of the ex ante surplus.

Note that this also has the interesting interpretation that the phenomena of inefficiency in our model is non-monotonic. That is, if trade costs are low, then a mis-allocation of resources is unlikely to occur because the inefficiency disappears as $t$ goes to zero. Similarly, if trade costs are very high, then inefficiency is also unlikely to occur because the foreign firm is most likely not competitive. However, as trade costs start to fall, the likelihood of an inefficient outcome increases. Regardless of the source of the trade costs (i.e. transport costs or artificial trade barriers), the model poses a challenge for the policy maker: since the allocation of resources can be inefficient, is it possible to use government policy to improve on the market outcome? Since the market outcome is not always inefficient, the policy will necessarily be contingent. 


\section{Globally Optimal Policy}

Start by considering a globally efficient policy. Such a policy has the objective of avoiding the inefficiency and ensuring that the lower cost firm serves the market. We study this case first because it provides a useful benchmark. The global planner, however, cannot directly observe the costs of the firms which are private information. She can only observe the prices that they charge.

A characteristic of the pricing functions that we derived in the previous section is that they are strictly monotone and therefore invertible. Consequently, a global planner can deduce from the announced prices what each firm's costs are, at least in a scenario

without intervention. Clearly, allowing the government to intervene changes the nature of the interaction, and may lead to pricing functions that are no longer monotone. This section therefore has two goals: to determine how the equilibrium pricing functions are altered if the global planner announces the objective of allocating production to the lowest cost firm. And second, to check whether the new pricing functions are indeed monotone, so that the policy-maker can deduce the information that is required to implement the policy.

Start by assuming that an equilibrium with strictly monotone pricing functions exists if the global planner announces her intention to intervene in order to allocate production to the lower cost firm. Note that the inefficiency in the (baseline) model always involved the foreign firm because the domestic firm never offered the lower price when it has the higher cost. This is not necessarily true anymore with policy intervention. Note further that we do not need monotonicity across the entire range. In particular, for $c_{1} \in[0, t]$, a single domestic price is sufficient as the domestic firm has always lower cost in this range.

If one firm has the higher cost (inclusive of trade costs in case of the foreign firm) but the lower price, the policymaker intervenes and allows the firm's competitor to serve the market at price

$$
\tilde{p}_{i}=\alpha c_{i}+(1-\alpha) p_{i}
$$

where $0 \leq \alpha \leq 1$. We choose this linear combination in order to allow for a wide range of possibilities: at one extreme, if $\alpha$ is chosen to be one, the government forces the firm that 
is awarded the market to sell at cost, while for $\alpha=0$ the government allows the firm to charge its original higher bid price. Clearly, the choice of $\alpha$ will influence the respective pricing behavior. In practice, forcing the firm, say the domestic firm, to sell at a certain price can be achieved by setting (ex post) the appropriate tariff. For example, imposing a tariff of $\tau$ on the lower price foreign firm translates into allowing the domestic firm to charge $\tilde{p}_{1}=p_{2}+\tau$.

Operating in an environment where trade policy is made contingent on the ranking of both prices and costs complicates the form of the expected profit functions. Now, not only are profits a function of prices (as was the case in 1), but also of contingent policy. To derive the profit of each firm under this regime requires working through the implications of choosing a price, conditional on the firm's own costs, the conjecture about the other firms pricing function and also the potential for policy intervention.

Let us start from the fact that each firm knows its own cost $c_{i}$ and treats the other firm's cost $c_{j}$ as a random variable with cumulative distribution function $F_{j}$. In this case, two important reference points on the support of $F_{j}$ are the own cost $c_{i}$, as this is the threshold that prompts the global policymaker to act (i.e. if $c_{i} \leq c_{j}$ the policy maker will award the market to firm $i$ if it does not have the lower price), and second, just as before, the cost that its own price implies on part of the other firm using the competitor's inverse bid function, i.e. $\phi_{j}\left(p_{i}\right)$, as this is the threshold for winning the market outright without intervention.

To be more precise, assume first that one firm, say the domestic firm, follows an aggressive pricing policy and sets a low price such that $\phi_{2}\left(p_{1}\right)+t<c_{1}$ (i.e. if the foreign firm set the price $p_{1}$ it would be associated with a cost draw of $c_{2}=\phi_{2}\left(p_{1}\right)$, which implies a total cost less than that of the domestic firm). In other words, if both firms charged the same price, it would turn out that the foreign firm has the lower overall cost, and this would prompt a policy intervention. Hence, in case of an aggressive pricing strategy, the domestic firm can win only if it has the lower cost, and this happens with probability $1-F_{2}\left(c_{1}-t\right){ }^{11}$

Now suppose that the domestic firm prices less aggressively such that $\phi_{2}\left(p_{1}\right)+t>c_{1}$. In

\footnotetext{
${ }^{11}$ Similarly, if the foreign firm charges a low price such that $\phi_{1}\left(p_{2}\right)<c_{2}+t$, it will win only if it has the lower overall cost, that is, if $c_{2}+t<c_{1}$ which happens with probability $1-F_{1}\left(c_{2}+t\right)$.
} 
that case, it will win outright if it charges the lower price which happens with probability $\left[1-F_{2}\left(\phi_{2}\left(p_{1}\right)\right]\right.$. In addition, if $c_{2}+t \in\left[c_{1}, \phi_{2}\left(p_{1}\right)\right]$, the competitor wins, but is overruled by the global policy maker who will give the market to the domestic firm at price $\tilde{p}_{1}$. This will happen with probability $\left[F_{2}\left(\phi_{2}\left(p_{1}\right)\right)-F_{2}\left(c_{1}-t\right)\right] .{ }^{12}$

Given own costs, conjectures about the rival's pricing strategy and the form of contingent protection, we can now determine the profit functions of both firms. The domestic firm's expected profits are equal to

$$
\pi_{1}= \begin{cases}{\left[1-F_{2}\left(c_{1}-t\right)\right]\left(p_{1}-c_{1}\right)} & \text { if } \phi_{2}\left(p_{1}\right)+t \leq c_{1}, \\ {\left[1-F_{2}\left(\phi_{2}\left(p_{1}\right)\right)\right]\left(p_{1}-c_{1}\right)+} & \\ {\left[F_{2}\left(\phi_{2}\left(p_{1}\right)\right)-F_{2}\left(c_{1}-t\right)\right]\left(\tilde{p}_{1}-c_{1}\right)} & \text { if } \phi_{2}\left(p_{1}\right)+t>c_{1}\end{cases}
$$

and the foreign firm's expected profits are equal to

$$
\pi_{2}=\left\{\begin{array}{cc}
{\left[1-F_{1}\left(c_{2}-t\right)\right]\left(p_{2}-c_{2}-t\right)} & \text { if } \phi_{1}\left(p_{2}\right) \leq c_{2}+t, \\
{\left[1-F_{1}\left(\phi_{1}\left(p_{2}\right)\right)\right]\left(p_{2}-c_{2}-t\right)} & \\
+\left[F_{1}\left(\phi_{1}\left(p_{2}\right)\right)-F_{1}\left(c_{2}+t\right)\right]\left(\tilde{p}_{2}-c_{2}-t\right) & \text { if } \phi_{1}\left(p_{2}\right)>c_{2}+t,
\end{array}\right.
$$

where $\tilde{p}_{1}, \tilde{p}_{2}$ are determined according to (9).

Intuitively, if a firm prices aggressively it will win outright whenever it has the lower cost. On the other hand, for $p_{i}$ above a threshold, the probability of winning outright decreases in its own price, whereas the probability of winning due to policy intervention depends positively on the price, but the margin might be lower in that case, depending on the policy rule $\tilde{p}$.

Given the expected profit it is now possible to determine the optimal pricing strategies. Differentiating equations (10a) and (10b) with respect to $p_{1}$ yields respectively (similar

\footnotetext{
${ }^{12}$ Similarly, if the foreign firm prices less aggressively such that $\phi_{1}\left(p_{2}\right)>c_{2}+t$, it wins straightaway with probability $\left[1-F_{1}\left(\phi_{1}\left(p_{2}\right)\right]\right.$ and will win the market for the price $\tilde{p}_{2}$ due to policy intervention with probability $\left[F_{1}\left(\phi_{1}\left(p_{2}\right)\right)-F_{1}\left(c_{2}+t\right)\right]$.
} 
expressions hold for the foreign firm):

$$
\frac{\partial \pi_{1}}{\partial p_{1}}= \begin{cases}{\left[1-F_{2}\left(c_{1}-t\right)\right]} & \text { if } \phi_{2}\left(p_{1}\right)+t \leq c_{1}, \\ {\left[1-F_{2}\left(\phi_{2}\left(p_{1}\right)\right)\right]-F_{2}^{\prime} \phi_{2}^{\prime}\left(p_{1}-\tilde{p}_{1}\right)} & \\ +(1-\alpha)\left(F_{2}\left(\phi_{2}\left(p_{1}\right)\right)-F_{2}\left(c_{1}-t\right)\right) . & \text { if } \phi_{2}\left(p_{1}\right)+t>c_{1}\end{cases}
$$

It is in general not clear whether it is $(12 \mathrm{a})$ or $(12 \mathrm{~b})$ that determines the best pricing policy. Expression (12a) shows that the marginal profit is constant for $\phi_{2}\left(p_{1}\right) \leq c_{2}+t$, and hence expected profits increase until $\phi_{1}\left(p_{2}\right)=c_{2}+t$. At $\phi_{2}\left(p_{1}\right)=c_{2}+t$, the profit curve has a downward kink, but it is not clear a priori whether (12b) is positive or negative at this point. If it is positive, profits increase further, and we find the optimal price by setting (12b) equal to zero. If not, $\phi_{1}\left(p_{2}\right)=c_{2}+t$ gives the maximum as profits decline beyond that point.

To gain insight into the role of contingent protection in determining the optimal pricing strategy, consider two extreme cases: Start with the situation where $\alpha=1$, which implies $\tilde{p}_{1}=c_{1}$. Note that this implies that the expression in $12 \mathrm{~b}$ is equal to

$$
\frac{\partial \pi_{1}}{\partial p_{1}}=\left[1-F_{2}\left(\phi_{2}\left(p_{1}\right)\right)\right]-F_{2}^{\prime} \phi_{2}^{\prime}\left(p_{1}-c_{1}\right)
$$

At the other extreme, when $\alpha=0$, the regulating authority allows the efficient firm to charge the price it had posted, i.e. $\tilde{p}_{1}=p_{1}$. The first-order condition then becomes linear everywhere:

$$
\frac{\partial \pi_{1}}{\partial p_{1}}=1-F_{2}\left(c_{1}-t\right) \quad \forall p_{1}
$$

This induces each firm to charge the maximum price of one because it knows that the chance of winning only depends on the cost realization. In this case, the price solely determines the profit margin if the firm happens to have the lower cost. However, all types choose this pricing policy, and hence the regulating authority cannot learn anything about the firm's type. Except for $\alpha=0$, we have the following clear result:

Proposition 1 If Assumptions 1 and 2 hold and the government intervenes according to (9) with $\alpha \in(0,1]$ in case of inefficiency, $F_{2}\left(c_{2}\right)=1 /(1-t)$, that is, firm 2 enters if 
$c_{2} \leq 1-t$. In case of entry, the equilibrium pricing functions are given by

$$
\begin{aligned}
& p_{1}\left(c_{1}\right)= \begin{cases}\frac{1+\alpha t}{1+\alpha} & \text { if } c_{1} \in[0, t], \\
\frac{1+\alpha c_{1}}{1+\alpha} & \text { if } c_{1} \in[t, 1],\end{cases} \\
& p_{2}\left(c_{2}\right)=\frac{1+\alpha\left(c_{2}+t\right)}{1+\alpha}
\end{aligned}
$$

Proof: See Appendix A.2.

Proposition 1 shows that both firms use symmetric pricing functions across the common range of overall costs. Appendix A.2 demonstrates that neither firm charges a price such that it will win only because it has a lower cost, instead both firms want to win straightaway. While it may be tempting to think that an equilibrium with symmetric pricing functions involves both firms charging lower prices, we see that this is incorrect in general. For example, the pricing functions are equal to $p_{1}=\left(1+c_{1}\right) / 2$ and $p_{2}=\left(1+c_{2}+t\right) / 2$ for the common support of overall costs if $\alpha=1$. Furthermore, both $\left(1+\alpha c_{1}\right) /(1+\alpha)$ and $\left(1+\alpha\left(c_{2}+t\right)\right) /(1+\alpha)$ increase with $\alpha$. The reason for this is that a high $\alpha$ gives more weight on the marginal cost and less weight on the posted price for the case of intervention (see (9)). It therefore becomes less attractive to win because of intervention so that the posted prices go up as to compensate for the decrease in expected profit after potential intervention.

These pricing functions allow us to answer the two questions posed at the beginning of the section. When a global contingent trade policy is announced, the pricing functions are symmetric over the range of common costs. This differs substantially from the outcome under laissez-faire where the foreign firm would systematically price lower than the domestic firm, given the same cost draw. Given that the two firms follow the same pricing policy over the set of common costs, inefficiency is no longer an equilibrium outcome. Consequently, the policy is effective in achieving its objective of a first best outcome. As for the question whether the policymaker can still infer the costs, note that the above pricing functions are strictly increasing where the supports overlap, and the domestic one is constant at the lower end. That is, the policymaker can infer costs and hence the policy is feasible. 
A further observation is that while global welfare is maximized by this policy, there are significant distributional implications that might undermine its adoption. In particular, the home country will have a lower expected welfare in some cases. For example, as $\alpha \rightarrow 0$, both firms employ very flat pricing functions that approach 1 . In this case, whenever the foreign firm has lower costs, the home country receives approximately zero welfare. As $t \rightarrow 0$, this occurs approximately half of the time. Under laissez-faire the domestic country gets positive consumer surplus for almost all cost draws and half of the time also gains domestic profits. Consequently, the home country is not always better off under a global contingent trade policy. In some sense the global policy acts as a "collusion device".

\section{Nationally Optimal Policy}

The potential for adverse distributional consequences associated with the implementation of a globally efficient regime suggests that contingent trade policy is more likely to be implemented at a national level, as is the case for example with antidumping policy. If contingent trade policy is left to national governments to design and administer, however, it will be conducted with the objective of maximizing national welfare, not global welfare. In contrast to the globally optimal policy, national governments do not only seek to correct the potential inefficiency, they also pursue rent shifting motives because they value the domestic firm's profit but not the foreign competitor's. Consequently, they intervene earlier and the foreign firm will be allowed to serve the domestic market only if its price is below the domestic firm's cost, because only in that case does the gain to domestic consumers dominate the profit loss of the domestic firm. If the foreign price lies between the domestic cost and the domestic price, on the other hand, then a prohibitive import tariff is imposed, and the domestic firm is allowed to set a price equal to (9). The objective of the domestic government to maximize national welfare suggests that there is likely to be a divergence from the efficient outcomes of the globally optimal benchmark. The interesting question then is whether or not the domestic policy mitigates or exaggerates the inefficiencies associated with market failure.

To answer this question we must, once again, address the same two issues as in the 
previous section: How does the announcement of such a policy influence the equilibrium pricing functions? And can the policy be successfully implemented? As before, we start by assuming that the pricing functions are monotonically increasing so that observing the bids allows the government to infer the respective costs. ${ }^{13}$

Provided that the foreign firm only gets to serve the market if its price is below the domestic firm's cost, the foreign firm's expected profit takes the following simple form:

$$
\pi_{2}\left(p_{2}, c_{2}\right)=\left[1-F_{1}\left(p_{2}\right)\right]\left(p_{2}-c_{2}-t\right)
$$

Note that the foreign firm's expected profit is independent of $p_{1}$, and therefore independent of the domestic firm's pricing behavior. Therefore the foreign firm's profit maximization can be solved independently of the domestic firm's pricing behavior.

Lemma 3 If a foreign firm for which $c_{2} \in[0,1-t]$ enters and a national government intervenes according to (9) as to maximize domestic welfare, the foreign firm's pricing and inverse pricing functions are respectively given by

$$
p_{2}\left(c_{2}\right)=\frac{1+c_{2}+t}{2} \quad \text { and } \quad \phi_{2}\left(p_{2}\right)+t=2 p_{2}-1 .
$$

Proof: For an interior solution, the first order condition is given by

$$
\frac{\partial \pi_{2}}{\partial p_{2}}=\left[1-F_{1}\left(p_{2}\right)\right]-F_{1}^{\prime}\left(p_{2}\right)\left(p_{2}-\phi_{2}\left(p_{2}\right)-t\right)=0
$$

which implies the following inverse bid function

$$
\phi_{2}\left(p_{2}\right)+t=p_{2}-\frac{1-F_{1}\left(p_{2}\right)}{f_{1}\left(p_{2}\right)} .
$$

Assumption 1 implies (16).

\footnotetext{
${ }^{13}$ Note that in this case we will only need this assumption for the domestic pricing function since the foreign price and not cost turns out to be the conditioning variable.
} 
We now turn attention to the domestic firm's behavior. Given the foreign firm's strategy, the domestic firm's profit function takes the following form:

$$
\pi_{1}=\left\{\begin{array}{cl}
p_{1}-c_{1} & \text { if } p_{1} \leq(1+t) / 2, \\
{\left[1-F_{2}\left(\phi_{2}\left(p_{1}\right)\right)\right]\left(p_{1}-c_{1}\right)+} & \\
{\left[F_{2}\left(\phi_{2}\left(p_{1}\right)\right)-F_{2}\left(\phi_{2}\left(c_{1}\right)\right)\right]\left(\tilde{p}_{1}-c_{1}\right)} & \text { otherwise }
\end{array}\right.
$$

where $\tilde{p}_{1}$ (see (9)) is the price that the government allows the domestic company to charge in case of policy intervention, as before. As long as the domestic firm charges a price below the lowest foreign price, that is $p_{1} \leq p_{2}\left(c_{2}=0\right)=(1+t) / 2$, it wins the market for sure, which leads to profits of $p_{1}-c_{1}$. If the domestic price lies above the threshold, there is a probability that it wins the market outright, represented by the first term of (19b), or it may win due to national policy intervention, which is reflected by the second term of (19b). We now derive the domestic firm's optimal pricing strategy resulting from the above profit function.

Proposition 2 If the national government maximizes national welfare and intervenes according to (9) with

$$
\alpha \in\left(\frac{1}{2}, \frac{1}{1+t}\right]
$$

a foreign firm for which $c_{2} \in[0,1-t]$ enters and the domestic firm's pricing function is given by

$$
p_{1}\left(c_{1}\right)=c_{1}+\frac{1-c_{1}}{2 \alpha} .
$$

Proof: See Appendix A.3.

Note that there is a tighter restriction on $\alpha$ compared to the globally optimal policy. First, given foreign pricing behavior, the domestic firm can win for sure if it charges $(1+t) / 2$. This is unprofitable only if the price $\tilde{p}_{1}$ imposed by the authority is not too close to the cost but leaves a substantially large profit. This is the reason for the upper bound on $\alpha$. Second, if $\alpha$ were small, the domestic firm would receive a profit close to its posted price in case of intervention. Since the domestic firm loses only if its price is above 
its rival's cost, it would go for the maximum (unity) price for a low $\alpha$, and not only if $\alpha=0$ as in the case of globally optimal policies. This is the reason for the lower bound on $\alpha$.
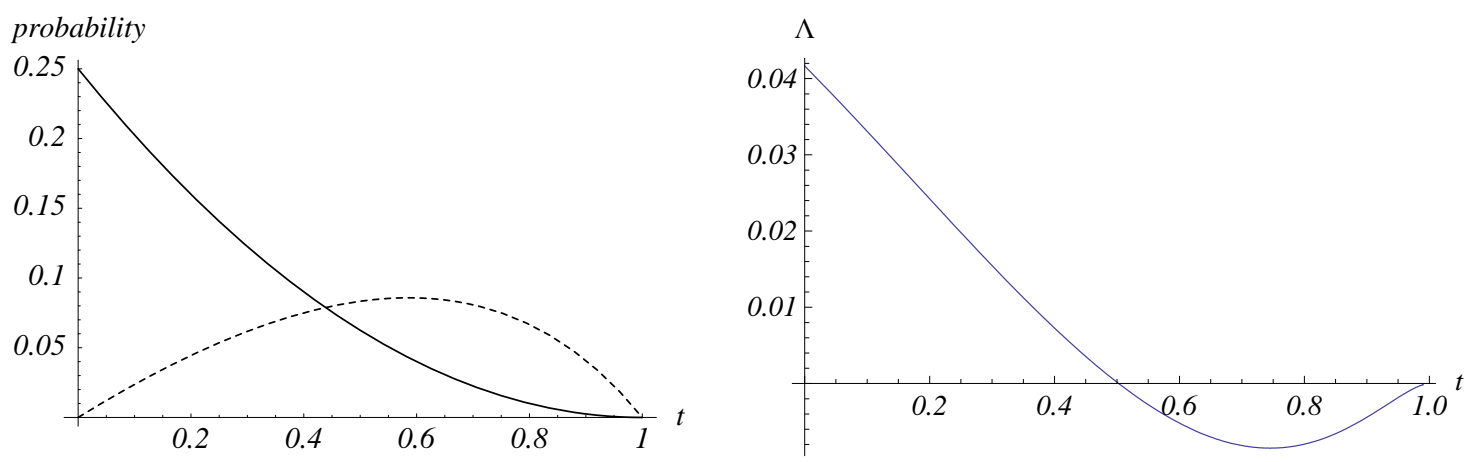

Figure 3: Comparison of Probabilities and Expected Losses

What are the consequences of a national contingent trade policy? Given the focus on allocative efficiency, this will be employed as the appropriate benchmark. In the case of the nationally efficient policy, there is again the possibility of inefficiency, that is, the higher cost firm ends serving the market. However, it can never be the case that the higher cost foreign firm serves the market. Instead the national policy favors the domestic firm which might end up serving the market despite having the higher cost. That is, the market failure that we identified in the laissez-faire scenario is now replaced by a (globally) inefficient allocation brought about by the government, only that the inefficiency now goes in the opposite direction.

To gain some idea of the likelihood of this scenario, Appendix A.3 shows that the probability of an inefficient outcome is given by $(1-t)^{2} / 4$. This enables us to compare the probabilities of the inefficient outcomes in the laissez-faire equilibrium (see the dashed lines in Figure 3's left panel) and for the nationally optimal policies (see the solid lines in Figure 3's left panel) respectively. In the right panel, $\Lambda$ is the difference in the unconditional expected loss between the nationally optimal policies and the laissez-faire equilibrium. As is evident, there is not an unambiguous ranking of these policies. 
In contrast to the laissez-faire outcome, the likelihood of the domestic policy inducing an inefficient allocation is monotonic - the inefficiency probability being much larger (lower) for low (high) levels of $t$. The reason is that the nationally optimal policy will call for intervention also when trade costs are low provided the foreign price (not foreign overall cost) exceeds the domestic cost. In this case, intervention happens mostly for rent shifting motives, as the likelihood of an allocative inefficiency under laissez faire is low. For higher trade costs, on the other hand, the foreign firm charges a higher price, and thus its probability of winning is low. The national government thus is rarely prompted to intervene. This is in contrast to the laissez-faire regime in which the foreign firm prices more aggressively. Therefore, the nationally optimal policy has a lower inefficiency probability for high trade costs.

Comparison to the laissez-faire case reveals that the nationally conducted contingent trade policy dominates for high trade costs, while laissez-faire is welfare superior (in expectation) for lower trade costs. Abstracting from other aspects, one could thus argue that nationally conducted antidumping policy, to take one example, might have been a good idea when trade costs were high. Once trade costs decrease with globalization, however, there comes a point when not allowing such nationally conducted policies would actually be preferable.

\section{Concluding remarks}

This paper has developed an efficiency theory of contingent trade policies. We show that there is a case for policy intervention if firms compete by prices under incomplete information. The reason is that the foreign firm is more aggressive without intervention. In case of a globally optimal policy, inefficiency will not occur because both firms employ the same pricing strategy across the common range of overall costs. Thus, the policy does not have to be applied but its announcement to apply it in the relevant cases is already successful. In case of a nationally optimal policy, only the domestic firm can be the source of inefficiency, and inefficiency is likely to occur for low trade costs compared to the laissez-faire. This observation strengthens the need for global policy coordination of contingent trade policies 
if markets become more integrated.

Global policy coordination, however, is not yet built into multilateral trade policies. Until now, trade policy is a national matter except for countries within the European Union. The need for global policy coordination with ongoing integration raises the question whether the existing trade agreements should continue to allow contingent trade policies in the first place. Furthermore, should future trade agreements give the option of interventions to supranational authorities, and not to individual countries? Given the potential distributional consequences which may arise if contingent trade policies act only on allocational efficiency, the establishment of such an authority seems unlikely.

This leaves us with the question whether the recent policy options, anti-dumping, safeguards and countervailing duties, become more and more vulnerable to policy interventions in the national interest of countries. Our paper has stressed that the likelihood of inefficiencies when these policies are carried out in the national interest increases with an ongoing integration. This leads us to the conclusion that the conditions under which countries are allowed to use these instruments should become rather more restrictive than be relaxed.

\section{Appendix}

\section{A.1 Equilibrium pricing strategies without policy intervention}

In case of entry, let $\gamma, \gamma \in[0,1-t]$ denotes the critical foreign type which is indifferent between entry and no entry. We will determine $\gamma$ below. Given that the domestic firm knows the size of $\epsilon$ and an observe this investment, it will update its beliefs if it observes entry such that the foreign types which enter will be uniformly distributed between 0 and $\gamma$. Consequently, the expected profits of both firms are equal to

$$
\begin{aligned}
& \pi_{1}\left(p_{1} ; c_{1}\right)=\left(1-\frac{\phi_{2}\left(p_{1}\right) x}{\gamma}\right)\left(p_{1}-c_{1}\right), \\
& \pi_{2}\left(p_{2} ; c_{2}\right)=\left(1-\phi_{1}\left(p_{2}\right)\right)\left(p_{2}-c_{2}-t\right) .
\end{aligned}
$$

First, let us establish that both firms will employ a price strategy such that the optimal price functions have a common upper and lower bound for those prices by which each firm is able to win demand. Let the lower (upper) bound be denoted by $p(\bar{p})$. If $p_{i}=p$, firm $i$ will win with certainty, so there is no reason to undercut this price. This confirms the 
common lower price bound, and hence $\phi_{1}(0)=\phi_{2}(0)=\underline{p}$. Suppose that the first-order conditions $(3)$ are fulfilled for all $p_{i} \in[\underline{p}, \bar{p}]$. We will now establish that

$$
\begin{aligned}
\bar{p} & =\frac{1+t+\gamma}{2}, \\
\phi_{1}(\bar{p}) & =\frac{1+t+\gamma}{2}, \quad \phi_{2}(\bar{p})=\gamma \\
\phi_{1}\left(p_{1}\right)^{2}=c_{1}, & \forall p_{1} \in[\bar{p}, 1]
\end{aligned}
$$

are part of the equilibrium pricing strategies. Note that (A.2) specifies that the domestic firm charges its cost for all prices above $\bar{p}$; in these cases, the domestic firm cannot win the market and will be beaten by the foreign firm with probability one. As we have assumed that the first-order conditions hold up to $\bar{p}$, we have to prove that no firm is better off by charging a higher price. As for the domestic firm, $\pi_{1}(\bar{p} ; \bar{p})=0$ because it will win with zero probability. A higher price leads also to zero profits as it does not change the zero win probability; hence, the domestic firm has no incentive to deviate from this strategy. The foreign firm is supposed to charge $\bar{p}$ for $c_{2}=\gamma$. Given that the domestic firm charges its cost for all prices above $\bar{p}$, the foreign firm profit is equal to

$$
\pi_{2}(\bar{p} ; \gamma)=(1-\bar{p})(\bar{p}-\gamma-t)=\frac{(1-t-\gamma)^{2}}{4}
$$

if it follows the prescribed strategy and

$$
\pi_{2}\left(p_{2}>\bar{p} ; \gamma\right)=\left(1-p_{2}\right)\left(p_{2}-\gamma-t\right)
$$

if it charges a higher price. Maximizing $\pi_{2}\left(p_{2}>\bar{p} ; \gamma\right)$ over $p_{2}$ leads to an optimal $p_{2}=\bar{p}$, and hence also the foreign firm has no incentive to deviate.

For all $p_{1}, p_{2} \in[\underline{p}, \bar{p}]$, the first-order conditions for (A.1) are

$$
\begin{array}{r}
\gamma-\phi_{2}\left(p_{1}\right)-\phi_{2}^{\prime}\left(p_{1}\right)\left(p_{1}-c_{1}\right)=0, \\
1-\phi_{1}\left(p_{2}\right)-\phi_{1}^{\prime}\left(p_{2}\right)\left(p_{2}-c_{2}-t\right)=0 .
\end{array}
$$

Note that each first-order condition depends on both inverse price functions. We now follow a solution concept similar to Krishna (2002) as to determine the boundary conditions and to simplify the differential equations. In equilibrium, $c_{i}=\phi_{i}\left(p_{i}\right)$, and using $p$ as the argument in the inverse price functions allows us to rewrite the first-order condition as

$$
\begin{aligned}
\left(\phi_{1}^{\prime}(p)-1\right)\left(p-\phi_{2}(p)-t\right) & =1-\phi_{1}(p)-p+\phi_{2}(p)+t \\
\left(\phi_{2}^{\prime}(p)-1\right)\left(p-\phi_{2}(p)\right) & =\gamma-\phi_{2}(p)-p+\phi_{1}(p) .
\end{aligned}
$$


Adding up yields

$$
\frac{-d}{d p}\left(p-\phi_{1}(p)\right)\left(p-\phi_{2}(p)-t\right)=1+t+\gamma-2 p,
$$

and integration implies

$$
\left(p-\phi_{1}(p)\right)\left(p-\phi_{2}(p)-t\right)=p^{2}-(1+t+\gamma) p+K,
$$

where $K$ denotes the integration constant. We can determine $K$ by using the upper boundary condition. For $p=\bar{p}$, the LHS of (A.5) is zero and we find that

$$
K=\frac{(1+t+\gamma)^{2}}{4}
$$

so that (A.5) reads

$$
\left(p-\phi_{1}(p)\right)\left(p-\phi_{2}(p)-t\right)=p^{2}-(1+t+\gamma) p+\frac{(1+t+\gamma)^{2}}{4}
$$

in equilibrium. Furthermore, $\phi_{1}(0)=\phi_{2}(0)=\underline{p}$ so that

$$
\underline{p}(\underline{p}-t)=\underline{p}^{2}-(1+t+\gamma) \underline{p}+\frac{(1+t+\gamma)^{2}}{4}
$$

which leads to

$$
\underline{p}=\frac{(1+t+\gamma)^{2}}{4(1+\gamma)}
$$

We can use (A.6) as to rewrite the first-order conditions such that each depends on a single inverse price function only:

$$
\begin{aligned}
& \gamma-\phi_{2}(p)=\phi_{2}^{\prime}(p) \frac{p^{2}-(1+t+\gamma) p+\frac{(1+t+\gamma)^{2}}{4}}{p-\phi_{2}(p)-t}=0 \\
& 1-\phi_{1}(p)=\phi_{1}^{\prime}(p) \frac{p^{2}-(1+t+\gamma) p+\frac{(1+t+\gamma)^{2}}{4}}{p-\phi_{1}(p)}=0 .
\end{aligned}
$$

Eqs. (A.2), (A.7) and (A.8) completely describe the equilibrium behavior of both firms in terms of their inverse price functions. ${ }^{14}$ Hence, they represent the solution to Stage II

\footnotetext{
${ }^{14}$ It is possible to derive explicit solutions for the inverse price functions. These functions, however, cannot be inverted as to solve for the price functions. The results are available upon request.
} 
of our game, given that no intervention will occur. As for stage I, eq. (A.3) allows us to determine the critical type $\gamma$ which will be indifferent between entry and no entry. This type's expected profit must be equal to the investment $\epsilon$ such that

$$
\gamma=1-t-2 \sqrt{\epsilon}
$$

An interior solution requires that $2 \sqrt{\epsilon}<1-t$. More importantly, as we deal with markets to which entry is easy, $\gamma \simeq 1-t$ for a $\epsilon$ sufficiently close to zero. For $\gamma \simeq 1-t$, (A.8) simplifies to

$$
\begin{aligned}
1-t-\phi_{2}(p) & =\phi_{2}^{\prime}(p) \frac{(1-p)^{2}}{p-\phi_{2}(p)-t} \\
1-\phi_{1}(p) & =\phi_{1}^{\prime}(p) \frac{(1-p)^{2}}{p-\phi_{1}(p)} .
\end{aligned}
$$

Because prices must not fall short of overall costs, $\phi_{1}^{\prime}, \phi_{2}^{\prime}>0$, and hence the solutions to (A.9) satisfy that the (inverse) price functions increase with the costs (prices). Solving these equations gives the inverse price functions

$$
\begin{aligned}
\phi_{1}(p) & =1-\frac{2(1-p)}{1-2(1-p)^{2} K_{1}} \\
\phi_{2}(p) & =1-\frac{2(1-p)}{1-2(1-p)^{2} K_{2}}-t
\end{aligned}
$$

where the $K_{i}$ 's are the constants of integration. Note that the domestic firm's price policy will no longer include a range of prices in which it will charge its cost (and win with zero probability) because

$$
\bar{p}=1 \text { and } \underline{p}=\frac{1}{2-t}
$$

for $\gamma \simeq 1-t$. Using the last condition, that is $\phi_{1}(0)=\phi_{2}(0)=1 /(2-t)$, we find that

$$
K_{1}=\frac{1}{2} \frac{t(2-t)}{(1-t)^{2}} \geq 0 \text { and } K_{2}=-K_{1} \leq 0 .
$$

Plugging $K_{1}$ and $K_{2}$ back into (A.10) and solving for $p$ yields (5).

To determine the probability that an inefficient outcome occurs, contingent upon entry of the foreign firm, we define the borderline $\tilde{c}_{2}\left(c_{1}\right)$ between the inefficient and the efficient 
set of cost draws at which the resulting prices are equal. Setting $p_{1}$ and $p_{2}$ in (5) equal to each other gives

$$
\tilde{c}_{2}\left(c_{1}\right)=1-\frac{1-c_{1}}{\sqrt{\frac{1-(2-t) t\left(2-c_{1}\right) c_{1}}{(1-t)^{2}}}}-t .
$$

The foreign firm prices more aggressively if $\tilde{c}_{2}\left(c_{1}\right)+t \leq c_{1}$ which is equivalent to

$$
\begin{aligned}
\left(1-c_{1}\right)\left(1-\frac{1-c_{1}}{\sqrt{\frac{1-(2-t) t\left(2-c_{1}\right) c_{1}}{(1-t)^{2}}}}\right) & \geq 0 \\
& \Leftrightarrow \sqrt{\frac{1-(2-t) t\left(2-c_{1}\right) c_{1}}{(1-t)^{2}}} \geq 1 \\
\Leftrightarrow & 1-(2-t) t\left(2-c_{1}\right) c_{1} \geq(1-t)^{2} .
\end{aligned}
$$

Note that the LHS decreases with $c_{1}$ and is thus at least equal to $1-2 t+t^{2}=(1-t)^{2}$ or larger which completes the proof for Lemma 2.

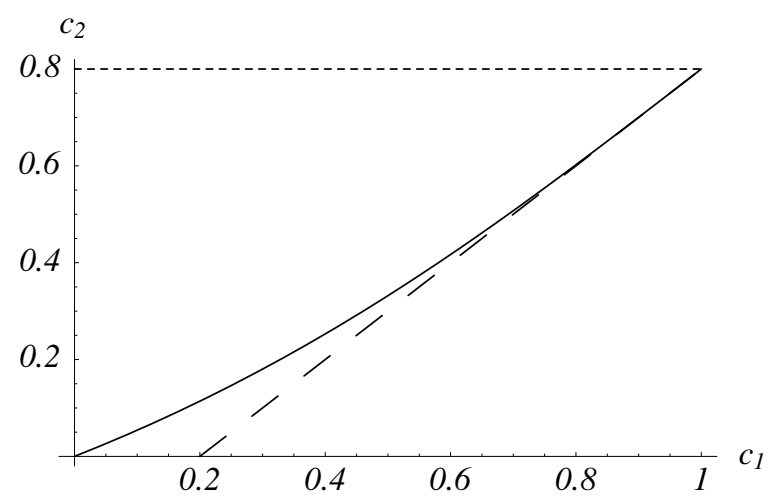

Figure 4: Inefficiency in the laissez-faire equilibrium

The probability of inefficiency can be best derived from two graphs in the $c_{2}-c_{1}-$ space. Figure 4 shows equation (A.12) for $t=0.2$ as the solid line. The broken line is the efficiency border $c_{2}=c_{1}-t$ where both firms are equally efficient. For $c_{1}<t$, the domestic firm is 
the efficient one in any case. In the laissez-faire equilibrium, the foreign firm wins (loses) if $\tilde{c}_{2}<(>) c_{1}$, and the domestic firm should win from a global perspective if $c_{2}>c_{1}-t$. The area between the two lines represents the inefficiency. Note that the size of the rectangle is $1-t$ due to the upper bound for $c_{2}$. The probability of inefficiency can thus be computed as the area below the solid line minus the area below the broken line, corrected by the factor $1 /(1-t)$ :

$$
\begin{array}{r}
\frac{1}{1-t}\left(\int_{0}^{1} \tilde{c}_{2}\left(c_{1}\right) d c_{1}-\int_{t}^{1}\left(c_{1}-t\right) d c_{1}\right) \\
=\frac{1}{2}+\frac{1}{(2-t)(1-t)}-\frac{1}{1-t}
\end{array}
$$

\section{A.2 Globally optimal contingent trade policies}

Our proof proceeds in two steps. First, we assume that all foreign firm for which $c_{2} \in$ $[0,1-t]$ will enter. Second, we will show that no foreign firm for which $c_{2} \in[1-t, 1]$ can be better off by entering, and no foreign firm for which $c_{2} \in[0,1-t]$ can be better off by not entering. In the main text, we have discussed the first derivative of the domestic firm w.r.t. its price in detail (see (12a) and (12b)). The corresponding expression for the foreign firm reads

$$
\begin{gathered}
\frac{\partial \pi_{2}}{\partial p_{2}}=\left[1-F_{1}\left(c_{2}+t\right)\right]>0 \\
\text { if } \phi_{1}\left(p_{2}\right) \leq c_{2}+t \\
\frac{\partial \pi_{2}}{\partial p_{2}}=\left[1-F_{1}\left(\phi_{1}\left(p_{2}\right)\right)\right]-F_{1}^{\prime} \phi_{1}^{\prime}\left(p_{2}-\tilde{p}_{2}\right)+(1-\alpha)\left(F_{1}\left(\phi_{1}\left(p_{2}\right)\right)-F_{1}\left(c_{2}+t\right)\right) \\
\quad \text { if } \phi_{1}\left(p_{2}\right)>c_{1}+t .
\end{gathered}
$$

Assume that both (12a) and (A.15) are not binding. Given Assumption 1, we find for our candidate pricing functions (14) that profits can be written as

$$
\begin{aligned}
\pi_{1} & =\frac{2\left(1+\alpha c_{1}\right)-(1+\alpha) p_{1}}{1-t} \\
\pi_{2} & =\left(p_{2}-c_{2}-t\right)\left(2-(1-\alpha)\left(c_{2}+t\right)-(1+\alpha) p_{2}\right)
\end{aligned}
$$


if the constraints imposed by (12a) and (A.15) do not bind. In (A.17), we assume for the domestic (foreign) profit that the domestic (foreign) firm expects the foreign (domestic) firm to charge a price according to (14). Maximization of these profits w.r.t. $p_{1}$ and $p_{2}$ reproduces (14). Furthermore,

$$
\begin{aligned}
& \phi_{2}\left(p_{1}\right)=c_{1} \quad \Leftrightarrow \quad p_{1}=\frac{1+\alpha\left(c_{1}+t\right)}{1+\alpha}<\frac{1+\alpha c_{1}}{1+\alpha} \\
& \phi_{1}\left(p_{2}\right)=c_{2} \quad \Leftrightarrow \quad p_{2}=\frac{1+\alpha\left(c_{2}+t\right)}{1+\alpha}=\frac{1+\alpha\left(c_{2}+t\right)}{1+\alpha}
\end{aligned}
$$

so that both (12a) and (A.15) are not binding (or just not binding for the foreign firm). Hence, our candidate pricing functions (14) are mutually consistent as they set both (12b) and (A.16) equal to zero for the common range of overall costs. Furthermore, they are increasing in costs. Note, however, that the domestic firm will win with certainty if $c_{1} \in[0, t]$. Hence, the domestic firm will not lower its price beyond $p_{1}\left(c_{1}=t\right)$ as it cannot increase its win probability any further. This proves that the pricing function are optimal if all foreign firm for which $c_{2} \in[0,1-t]$ will enter, and all other firms will stay away. Now note that the any foreign firm for which $c_{2} \in[1-t, 1]$ cannot make any profit by entering as its break even price is unity. Furthermore, no firm for $c_{2} \in[0,1-t]$ cannot be better off by not entering as there is a positive probability that it will win the market. This completes the proof of Proposition 1.

\section{A.3 Nationally optimal contingent trade policies}

Below the lowest price of the foreign firm, the domestic firm's profit function is strictly increasing in $p_{1}$. This implies that the domestic firm will never set a price below $(1+t) / 2$ but instead charge $(1+t) / 2$ which leads to profits of $\hat{\pi}_{1}=(1+t) / 2-c_{1}$.

Above the threshold, the first order condition for (19b) leads to (20). Note that this function is monotonically increasing as long as $\alpha>1 / 2$. For $\alpha=1 / 2$ the domestic firm charges a price of one, independent of its cost draw. For a lower $\alpha$, that is, when the government allows the domestic firm to charge a relatively high price in case of intervention, the first order condition would imply a decreasing price above unity, but given our assumption that the willingness to pay is bounded at one, it charges a price of one for all $\alpha \leq 1 / 2$.

For $\alpha>1 / 2$ we need to check that the profit resulting from the above pricing rule exceeds the profit $\hat{\pi}_{1}$ that the firm would obtain by charging the lowest price of the foreign competitor. Plugging (20) back into (19b) results in the following condition:

$$
\pi_{1}^{*}=\frac{(1-c)^{2}}{2(1-t) \alpha} \geq \hat{\pi}_{1}=\frac{1+t}{2}-c .
$$


This condition is satisfied for all cost draws $c_{1} \in[0,1]$ as long as $\alpha \leq 1 /(1+t)$. As in the case of globally optimal policies, any foreign firm for which $c_{2} \in[1-t, 1]$ cannot make any profit by entering as its break even price is unity. Furthermore, no firm for $c_{2} \in[0,1-t]$ cannot be better off by not entering as there is a positive probability that it will win the market. This completes the proof of Proposition 2.

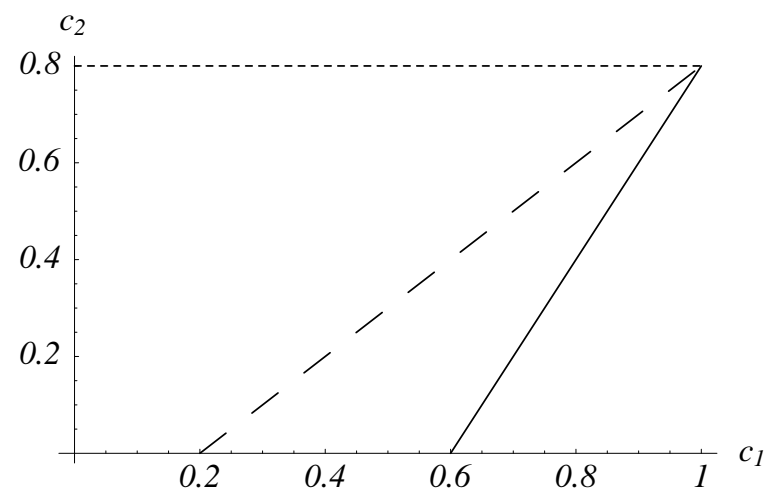

Figure 5: Inefficiency for nationally optimal policies

As for the inefficiency probability, we proceed similarly as in Appendix A.1. Figure 5 also shows the efficiency border as a broken line for $t=0.2$. However, now the domestic firm is the source of potential inefficiency. Setting (16) and (20) equal to each other, we get a critical $\hat{c_{2}}=2 c_{1}-(1+t)$ which is given by the solid line. This line gives the costs for which both firms charge the same prices , and hence the domestic firm wins if $c_{2}$ is larger. This function is only defined for $c_{1} \in[(1+t) / 2,1]$. The probability of inefficiency is given by the area below the broken line minus the area below the solid line, corrected by $1 /(1-t)$ :

$$
\frac{1}{1-t}\left(\frac{(1-t)^{2}}{2}-\frac{1}{2}\left(1-\frac{1+t}{2}\right)(1-t)\right)=\frac{(1-t)^{2}}{4}
$$




\section{References}

Anderson, J. (1992). Domino dumping, i: competitive exporters. American Economic Review, 82, 65-83.

Bagwell, K. and Staiger, R. (1990). A theory of managed trade. American Economic Review, 80, 779-795.

Beshkar, M. and Bond, E. (2010). Transaction costs, asymmetric countries and flexible trade agreements..

Blonigen, B. and Prusa, T. (2003). Antidumping. In Choi, E. K. and Harrigan, J. (Eds.), Handbook of International Trade, pp. 251-284. Blackwell.

Bown, C. (2007). Global antidumping database. World Bank, Development Research Group, Trade Team, Washington, D.C.

Brander, J. and Krugman, P. (1983). A 'reciprocal dumping' model of international trade. Journal of International Economics, 15, 313-321.

Chisik, R. (2003). Gradualism in free trade agreements: a theoretical justification. Journal of International Economics, 59(2), 367-397.

Feenstra, R. (2004). Advanced International Trade. Theory and Evidence. Princeton University Press.

Fischer, H. and Prusa, T. (2003). Wto exceptions as insurance. Review of International Economics, 11, 745-757.

Hillberry, R. and McCalman, P. (2011). What triggers an anti-dumping petition? finding the devil in the detail..

Horn, H., M. G. and Staiger, R. (2010). Trade agreements as endogenously incomplete contracts. American Economic Review, 100, 394-419.

Kolev, D. and Prusa, T. (2002). Dumping and double crossing: the (in)effectiveness of costbased trade policy under incomplete information. International Economic Review, 43, 895-918.

Krishna, V. (2002). Auction Theory. Academic Press.

Maggi, G. and Staiger, R. (2008). On the role and design of dispute settlement in international trade agreements. Working paper 14067, NBER. 
Maggi, G. and Staiger, R. (2009). Breach, remedies and dispute settlement in international trade agreements. Working paper 15460, NBER.

Matschke, X. and Schottner, A. (2008). Antidumping as strategic trade policy under asymmetric information. Working papers 2008-19, University of Connecticut, Department of Economics.

Miyagiwa, K. and Ohno, Y. (2007). Dumping as a signal of innovation. Journal of International Economics, 71, 221-240.

Staiger, R. and Wolak, F. (1992). The effect of domestic antidumping law in the presence of foreign monopoly. Journal of International Economics, 32, 265-287. 